\title{
Inverse association of esophageal eosinophilia with Helicobacter pylori based on analysis of a US pathology database
}

\author{
Evan S. Dellon, MD, MPH ${ }^{1,2}$, Anne F. Peery, MD $^{1,2}$, Nicholas J. Shaheen, MD, MPH ${ }^{1,2}$, \\ Douglas R. Morgan, MD, MPH ${ }^{1,2}$, Jennifer M. Hurrell, DO ${ }^{3,4}$, Richard H. Lash, MD $^{4}$, and \\ Robert M. Genta, MD 3,4 \\ ${ }^{1}$ Center for Esophageal Diseases and Swallowing, University of North Carolina School of \\ Medicine, Chapel Hill, NC \\ ${ }^{2}$ Center for Gastrointestinal Biology and Disease, Division of Gastroenterology and Hepatology, \\ Department of Medicine, University of North Carolina School of Medicine, Chapel Hill, NC \\ ${ }^{3}$ Dallas Veterans Affairs Medical Center, University of Texas Southwestern Medical Center at \\ Dallas \\ ${ }^{4}$ Caris Research Institute, Caris Life Sciences, Irving, TX
}

\begin{abstract}
Background \& Aims-Eosinophilic esophagitis (EoE) is of increasing prevalence and thought to result from allergic processes. Helicobacter pylori has been inversely associated with allergic diseases, but there is no known relationship between $H$. pylori, EoE and esophageal eosinophilia. We investigated the association between esophageal eosinophilia and $H$. pylori infection.

Methods-We performed a cross-sectional study of data, collected from a United States pathology database, on 165,017 patients in the US who received esophageal and gastric biopsies from 2008 and 2010. Patients with and without $H$. pylori on gastric biopsy were compared and odds of esophageal eosinophilia were determined.
\end{abstract}

Results-From the data analyzed, 56,301 (34.1\%) had normal esophageal biopsies, 5,767 (3.5\%) had esophageal eosinophilia, and 11,170 (4.8\%) had H. pylori infection. Esophageal eosinophilia was inversely associated with $H$. pylori (odds ration [OR]: $0.77,95 \%$ confidence interval [CI]:

(C) 2011 The American Gastroenterological Association. Published by Elsevier Inc. All rights reserved.

Corresponding Author: Evan S. Dellon MD, MPH, CB\#7080, Bioinformatics Building, 130 Mason Farm Rd. UNC-CH, Chapel Hill, NC 27599-7080, Phone: (919) 966-2513, Fax: (919) 843-2508, edellon@med.unc.edu.

Disclosures: Robert M. Genta and Richard H. Lash are employed by Caris Life Sciences, Irving, Texas, and are shareholders in the company. There are no other potential conflicts of interest for any of the authors pertaining to this study

Author contributions (all authors approved this final draft): Dellon: project conception and design; data acquisition; data analysis; data interpretation; drafting of the article and critical revision

Perry: data analysis; data interpretation; drafting of the article and critical revision

Shaheen: project conception and design; data interpretation; critical revision; supervision

Morgan: data interpretation; critical revision

Hurrell: data acquisition/database construction; critical revision

Lash: data acquisition/preparation and implementation of standardized pathology codes; critical revision

Genta: project conception and design; data acquisition; data interpretation; critical revision; supervision

Publisher's Disclaimer: This is a PDF file of an unedited manuscript that has been accepted for publication. As a service to our customers we are providing this early version of the manuscript. The manuscript will undergo copyediting, typesetting, and review of the resulting proof before it is published in its final citable form. Please note that during the production process errors may be discovered which could affect the content, and all legal disclaimers that apply to the journal pertain. 
0.69-0.87). Compared to patients with normal esophageal biopsies, odds of $H$. pylori were reduced among patients with $\geq 15$ eosinophils per high-power field (eos/hpf) (OR 0.79; $95 \% \mathrm{CI}$ $0.70-0.88$ ), $\geq 45$ eos/hpf (OR 0.75; 0.61-0.93), $\geq 75$ eos/hpf (OR 0.72; 0.62-0.83), and $\geq 90$ eos/ hpf (OR 0.52; 0.31-0.87) (p for trend <0.001). A similar dose-response trend was observed for increasing clinical suspicion for EoE and decreasing prevalence of $H$ pylori. Additionally, severity of histologic effects of $H$. pylori was inversely associated with esophageal eosinophilia. All trends held in multivariate analysis.

Conclusions-In a large cross-sectional analysis, $H$. pylori infection was inversely associated with esophageal eosinophilia. This relationship could have implications for the pathogenesis and epidemiology of EoE.

\section{Keywords}

Epidemiology; esophagus; inflammation; histologic analysis; bacterial infection

\section{Introduction}

Eosinophilic esophagitis (EoE) is a chronic disease of the esophagus characterized by dysphagia and dense esophageal eosinophilia in the absence of gastroesophageal reflux disease (GERD). ${ }^{1}$ First described in 1978 and initially felt to be rare, ${ }^{2,3}$ the incidence and prevalence of EoE have rapidly increased over the past decade. ${ }^{4-8}$ Currently, between 5$15 \%$ of patients undergoing endoscopic evaluation for dysphagia will have EoE, ${ }^{9-11}$ and greater than $50 \%$ of patients presenting to an emergency room with food impaction are now diagnosed with EoE. ${ }^{12,13}$ The pathogenesis of EoE is believed to be an immune-mediated allergic process, ${ }^{14}$ but the etiology is unknown.

Given the dramatic epidemiologic shift regarding EoE, environmental exposures have been postulated to play a role. ${ }^{15}$ One early life exposure, Helicobacter pylori, has been inversely associated with conditions such as asthma, allergic rhinitis and atopic dermatitis, and biologic plausibility for a protective role of $H$. pylori in allergic disease is emerging. ${ }^{16-19}$ While there is an ecologic association between the decreasing prevalence of $H$. pylori and the increase in EoE, the association between H. pylori infection, EoE, and esophageal eosinophilia is poorly understood.

The primary objective of this study was to determine the association between esophageal eosinophilia and $H$. pylori in a large set of gastric and esophageal biopsy specimens. We hypothesized that the presence of $\mathrm{H}$. pylori would be inversely associated with increasing esophageal eosinophilia. The secondary objectives were to determine the association between patients suspected of having EoE and $H$. pylori, and between esophageal eosinophilia and different $H$. pylori disease manifestations in the stomach. We hypothesized that the presence of $H$. pylori would be inversely associated with increasing clinical suspicion for EoE, and that esophageal eosinophilia would be inversely associated with more severe manifestations of H. pylori.

\section{Methods}

\section{Study Design and Data Source}

This is a cross-sectional study of all patients with esophageal biopsies examined between January 1, 2008 and November 26, 2010 by pathologists at Caris Life Sciences. The Caris Institutional Review Board and the University of North Carolina Institutional Review Board approved the study. 
Caris Life Sciences is a specialized pathology laboratory serving outpatient endoscopy centers throughout the United States. They review samples from 43 states, Washington D.C., and Puerto Rico, with central specimen processing in one of three labs (Irving, Texas; Phoenix, Arizona; Boston, Massachusetts). Each laboratory follows identical sectioning and staining procedures. An experienced group of sub-specialty trained gastrointestinal pathologists originally reviewed the slides for clinical purposes. Biopsy interpretation is performed using a standardized protocol with uniform diagnostic criteria. All biopsy reports are deposited into a central database, which also includes information about patient age, sex, and indication for esophagogastroduodenoscopy (EGD). For the purposes of this study, a deidentified database of pre-existing records from unique patients with esophageal biopsies was generated.

\section{Study population}

Cases comprised all patients with esophageal eosinophilia on esophageal biopsy. By definition, cases had histology demonstrating a prominent epithelial infiltration of eosinophils, as described in standardized coding by pathologists (either as "active esophagitis with increased intraepithelial eosinophils" or as an "eosinophilic esophagitis pattern or injury"). ${ }^{20}$ Cases were termed "any esophageal eosinophilia".

Controls were all patients with normal esophageal biopsies (unremarkable squamous mucosa). By definition, controls had no evidence of esophageal eosinophilia or other pathologic processes such as non-eosinophilic inflammation of any type, epithelial erosion or ulceration, infection with viral or fungal pathogens, or cellular metaplasia, dysplasia, or neoplasia.

The main exposure was the presence of active H. pylori infection on gastric biopsy. A diagnosis of Helicobacter gastritis was made when $H$. pylori organisms were detected in a gastric biopsy using an $H$. pylori-specific immunohistochemical stain (anti-H. pylori rabbit polyclonal antibody; Cell-Marque, Rocklin, CA), and there was concomitant chronic and/or active inflammation (with or without intestinal metaplasia) in the gastric mucosa, per the updated Sydney classification. ${ }^{21,22}$

Other histologic characteristics of interest included a quantification of the severity of esophageal eosinophilic density in ranges of eosinophils per high-power (400x) field (eos/ hpf; area per hpf $=0.237 \mathrm{~mm}^{2}$ ), the presence of eosinophilic microabscesses (defined as clusters of $\geq 4$ contiguous eosinophils), ${ }^{23}$ the presence of reflux esophagitis (defined as a mixed active/chronic inflammatory pattern with squamous papillomatosis and basal hyperplasia), the presence of intestinal metaplasia (Barrett's esophagus), and the presence of infectious esophagitis (defined as histopathologic evidence of either candida, herpes simplex virus, or cytomegalovirus on esophageal biopsy specimens).

Clinical characteristics of interest included upper gastrointestinal symptoms or conditions as derived from the indication for endoscopy (ie: suspected EoE; dysphagia symptoms; reflux symptoms or GERD (defined as a report of heartburn, regurgitation, or reflux); screening or follow-up of a known diagnosis of Barrett's esophagus; abdominal pain or dyspepsia; chest pain; nausea or vomiting; and weight loss or failure to thrive).

\section{Statistical Analysis}

Means and standard deviations were reported for continuous variables. Proportions were reported for categorical data. Bivariate analyses were performed using Student's t-test for continuous characteristics or Pearson's chi-square for categorical characteristics. Unadjusted odds ratios (ORs) were calculated to assess the association between case-control status and the presence of $H$. pylori. To adjust for potential confounders noted on bivariate analysis, 
multivariate analyses were performed using logistic regression. A backwards elimination strategy was used to reduce the model, retaining those covariates whose removal would have caused a change in estimate of greater than $10 \%$ in the estimate of the effect of the association between $H$. pylori and esophageal eosinophilia. The initial model contained age, sex, dysphagia, abdominal pain, and reflux symptoms as defined above. Age was retained in the final model. Analyses were performed with STATA (version 11.0, College Station, Texas).

\section{Sensitivity Analyses}

We planned for several a priori sensitivity analyses. First, a dose-response analysis was performed for the association between $H$. pylori and increasing levels of esophageal eosinophilia on biopsy (nested categories of $\geq 15, \geq 45, \geq 75$, and $\geq 90$ eos/hpf), and a $p$ for trend was calculated. These categories were chosen empirically based on the available data distributions. In addition, there were some reports where the level of esophageal eosinophilia was included in the text of the pathology report but there was not an associated standardized pathology code. These cases were included in the " $\geq 15$ eos/hpf" category but were not previously included in the "any esophageal eosinophilia" case definition as described above.

A second analysis was performed to approximate an increasing clinical likelihood of EoE. We began with patients who were unlikely to have EoE who had pathology consistent with reflux esophagitis. We then applied progressively restrictive limits on the presence of esophageal eosinophilia. First, we defined a group termed "histologic eosinophilic esophagitis" comprised of only patients with the standardized pathology interpretation code of "eosinophilic esophagitis pattern of injury" on esophageal biopsy (as outlined above). We then restricted this group to those who also had an EGD indication of dysphagia or clinical suspicion for EoE, and had no histologic evidence of reflux esophagitis or Barrett's esophagus. This definition was then further limited to patients who also had eosinophilic microabscesses in the esophageal epithelium. The last group definition included only patients with $\geq 90$ eos/hpf on esophageal biopsy. We also performed a sub-analysis of the association between $H$. pylori and esophageal eosinophilia based on whether the esophageal biopsy was taken from the proximal or distal esophagus.

The final sensitivity analysis examined the association of "histologic eosinophilic esophagitis" with different manifestations of $H$. pylori disease in the stomach, including chronic active gastritis without $H$. pylori present, chronic active gastritis with $H$. pylori present, and intestinal metaplasia present (with or without $H$. pylori). The purpose was to investigate esophageal eosinophilia from the perspective of increasing severity of infection with H. pylori. ${ }^{24,25}$

\section{Results}

\section{Patient and biopsy characteristics}

Between January 1, 2008 and November 26, 2010, a total of 233,662 unique patients had esophageal biopsies reviewed (Table 1). The mean age was 55.8 years and $46.1 \%$ were male. The most common indications for endoscopy were GERD (48.6\%), abdominal pain (32.9\%) and dysphagia (22.6\%). There were 26,982 (11.6\%) patients who underwent endoscopy for suspected EoE on a clinical basis. We identified 165,017 patients with both esophageal and gastric biopsies. Of these patients, 56,301 (34.1\%) had normal esophageal biopsies, 5,767 (3.5\%) had "any esophageal eosinophilia", and 11,170 (6.8\%) had H. pylori on gastric biopsy (Table 1). While there were many statistical differences given the large sample size between those who had both esophageal and gastric biopsies and those with 
esophageal biopsies only (Table 1), for the large majority of variables the absolute different between groups was $1 \%$ or less, differences that were not clinically significant.

Of those with both esophageal and gastric biopsies, patients with esophageal eosinophilia were significantly younger (44 vs 53 years; $\mathrm{p}<0.001$ ) and more likely to be male (62\% vs $35 \% ; \mathrm{p}<0.001$ ) compared with patients with normal esophageal biopsies (Table 2). They were also more likely to have an endoscopy indication for suspected EoE or dysphagia and less likely to have an indication of GERD, abdominal pain or chest pain. Compared to patients without $H$. pylori, patients with $H$. pylori were more likely to have an upper endoscopy indication for abdominal pain and less likely to have an indication for suspected EoE, dysphagia, or Barrett's esophagus (Table 3).

\section{Esophageal eosinophilia and $\mathrm{H}$. pylori}

The presence of "any esophageal eosinophilia" was inversely associated with $H$. pylori (OR: 0.77, 95\% CI: 0.69-0.87) (Table 4). Compared to patients with normal esophageal biopsies, there were reduced odds of $H$. pylori for patients with $\geq 15$ intraepithelial eosinophils per high-power field (eos/hpf) (OR 0.79; 95\% CI 0.70-0.88), $\geq 45$ eos/hpf (OR 0.75; $0.61-$ 0.93 ), $\geq 75$ eos/hpf (OR 0.72; 0.62-0.83), and $\geq 90$ eos/hpf (OR 0.52; 0.31-0.87) (p for trend $<0.001)$. These associations held after adjusting for potential confounding factors on multivariate analysis (Table 4).

Increasing clinical suspicion for EoE was also associated with decreasing odds of $H$. pylori. Compared to patients with normal esophageal biopsies, patients with no suspicion of EoE and reflux esophagitis on biopsy had a borderline inverse association with H. pylori (OR 0.95; 95\% CI 0.90-0.99). Patients with "histologic eosinophilic esophagitis" (as defined above) had reduced odds of $H$. pylori (OR 0.72; 0.62-0.83). This inverse association was stronger when limited to those with dysphagia or a clinical suspicion of EoE, no reflux or Barrett's esophagus, and eosinophilic microabscesses, (OR 0.63; 0.45-0.87). Again, all associations held after adjusting for potential confounding factors on multivariate analysis (Table 4).

There were also differences when evaluating the presence of esophageal eosinophilia in patients with different manifestations of gastritis and H. pylori. Compared to patients with normal gastric biopsies, there were reduced odds of "histologic EoE" among patients with chronic active gastritis but no identifiable $H$. pylori (OR 0.86; 95\% CI 0.64-1.17), patients with chronic active gastritis and $H$. pylori present (OR $0.69 ; 0.59-0.81)$, and patients with intestinal metaplasia with or without $H$. pylori (OR 0.34; $0.23-0.51$; p for trend $<0.001$ ). These associations also held on multivariate analysis (Table 5).

Assessment of biopsy location (proximal vs. distal) as an effect modifier of the association between $H$. pylori infection and esophageal eosinophilia demonstrated no significant difference based on location of the esophageal biopsy (data and full models not shown).

\section{Discussion}

Over the past decade, EoE has become a major cause of dysphagia and morbidity and is commonly encountered in GI practice. ${ }^{1,4-6,8-13,26-28}$ With such a rapidly evolving epidemiology, it is plausible that environmental factors play a role. In some cases specific food allergens or environmental triggers can be identified. ${ }^{29-32}$ However, the etiology for the dramatic rise in the incidence of EoE is unknown.

The present study utilized a nationwide pathology database to assess the association between esophageal eosinophilia and $\mathrm{H}$. pylori, and the results were striking. We found a strong 
inverse association between $H$. pylori and esophageal eosinophilia, and as the level of esophageal eosinophilia increased, the odds of $H$. pylori decreased. With increasingly stringent case definitions approximating EoE on a clinical basis, the odds of $H$. pylori also decreased. In addition, the odds of esophageal eosinophilia were lower with progressively chronic manifestations of $\mathrm{H}$. pylori disease, as manifest by chronic active gastritis and intestinal metaplasia.

Despite the common nature of both conditions, the literature describing the relationship between $H$. pylori infection and EoE is scant and conflicting. An inverse association of $H$. pylori and esophageal eosinophilia has been suggested in one prior report. ${ }^{6}$ In this secondary analysis of a population-based study of the prevalence of Barrett's esophagus, distal esophageal biopsies were re-reviewed for eosinophil counts. However, there were only 48 patients with esophageal eosinophilia, and 8 with $\mathrm{H}$. pylori. The reported OR in this study was 0.41 , similar to our results. In contrast, a study of eosinophilia throughout all segments of the GI tract found that patients with H. pylori gastritis had somewhat higher esophageal eosinophil counts than patients without $H$. pylori. This study, too, was limited by small numbers, with only 8 patients with eosinophil counts $\geq 15$ eos/hpf. ${ }^{33}$ To our knowledge, there have been no prior investigations that also examined esophageal eosinophilia in relation to the manifestation of $H$. pylori in the stomach.

There are several possible explanations for our findings. H. pylori has been inversely associated with conditions such as asthma, allergic rhinitis and atopic dermatitis. ${ }^{16-19}$ Given that EoE is believed to be an allergic condition, it makes sense that the same association exists. The hygiene hypothesis has been used to attribute the recent increase in all allergic diseases to improved sanitation and reductions in childhood infections, and H. pylori is typically contracted during childhood. ${ }^{15,16,34}$ From a mechanistic perspective, a Th2mediated allergic response is involved in the pathogenesis of EoE, ${ }^{14,35-37}$ whereas $H$. pylori may drive a Th1 response ${ }^{16}$ with the regulatory $\mathrm{T}$ cell population further modulating the Th1-Th2 balance. It is intriguing to hypothesize, as has been proposed with other allergic conditions, ${ }^{16,38}$ that early infection with $H$. pylori might predispose toward a Th1 response and "protect" from an allergic Th2 response and in turn esophageal eosinophilia. The observations of the lower odds of $H$. pylori with increasing esophageal eosinophilia, and also the low odds of esophageal eosinophilia in subjects with intestinal metaplasia (arguably a manifestation of chronic infection and potentially a committed Th1 inflammatory response to $H$. pylori ${ }^{24}$ ), may lend some credence to this hypothesis. We observe that the exact mechanisms of immune modulation of allergy by chronic infections are largely unknown, with the model of Th1 versus Th2 responses most likely representing a simplication. ${ }^{39}$ For example, recent studies have demonstrated that $H$. pylori may inhibit the Th17 response and alter the T regulatory cell balance, ${ }^{39}$ and $H$. pylori derived DNA itself may directly inhibit a Th1 response..$^{40}$ It remains to be determined whether our findings are attributable to physiologic reflux of $H$. pylori or its DNA, a field effect related to systemic immune alterations, or a different mechanism. In the present study, however, we did not see a clear trend by biopsy level in the esophagus for the inverse association between $\mathrm{H}$. pylori and esophageal eosinophilia, arguing against direct exposure of $H$. pylori or its DNA as a causal factor for the observed associaton.

Several potential limitations must be considered when interpreting these data. First, because this study was retrospective and cross-sectional in nature, we were unable to draw conclusions about causality or mechanisms, only about associations. Second, we had to restrict our primary outcome to the presence of esophageal eosinophilia, not to EoE itself. This is because current consensus guidelines hold that EoE is a clinicopathologic condition and require exclusion of competing causes of esophageal eosinophilia, including GERD, before the diagnosis of EoE can only be made on a clinical basis. ${ }^{1}$ However, we recognized 
this possible limitation while designing the study and incorporated sensitivity analyses to specifically address this issue. The results of these analyses further support our conclusions. In particular, we observed a stronger inverse association as we assessed progressively more specific EoE case definitions with higher eosinophil counts, supportive histopathologic findings like eosinophilic microabscesses, and exclusion of reflux esophagitis and Barrett's esophagus.

Issues of possible confounding must also be considered. One possibility is that $H$. pylori infection is not causally protective for esophageal eosinophilia but is instead a marker for general microbial or environmental exposures, or other allergic conditions. If this were the case, however, it would be unlikely that the odds of esophageal eosinophilia would be lower with a chronic manifestation of $H$. pylori such as intestinal metaplasia. It is also possible that GERD or PPI use could be confounding factors. H. pylori is harder to detect in patients on concurrent PPI therapy ${ }^{41}$ thus if patients had esophageal eosinophilia due to GERD and were treated with a PPI, it stands to reason that the prevalence of $H$. pylori would be lower. In addition, $H$. pylori can reduce gastric acid section which may also have an impact on esophageal eosinophilia. However, when we controlled for reflux symptoms on multivariable analysis there was no change in the observed association, and when patients with reflux esophagitis or histologically-confirmed Barrett's esophagus were excluded in our more stringent case definition, the odds ratio for $H$. pylori was farther from the null, the opposite of what would be expected if GERD were a confounder. The careful pathologic characterization of a large number of esophageal biopsies using a standardized system of interpretation, in combination with the sensitivity analyses performed for this study, lend validity to our results. This is by far the largest number of subjects with esophageal eosinophilia analyzed in the medical literature.

In conclusion, we found that there was a strong inverse association between $H$. pylori infection and esophageal eosinophilia in biopsies from a large U.S. national pathology database with a patient population reflective of general GI practice. The odds of $H$. pylori decreased in a dose-response fashion with increasing levels of esophageal eosinophilia and with increasingly restrictive pathologic definitions of EoE. In addition, the odds of esophageal eosinophilia decreased with chronic manifestations of $H$. pylori gastritis and intestinal metaplasia. While the results of this study cannot speak to causality or biologic mechanisms, this association may have important implications for future research into understanding the pathogenesis and evolving epidemiology of EoE.

\section{Acknowledgments}

Grant support: This work is funded, in part, by NIH award number T32 DK 07634 (AFP), NIH award number KL2RR025746 from the Nation Center for Research Resources (ESD) and a Junior Faculty Development Award from the American College of Gastroenterology (ESD).

\section{Abbreviations}

$\begin{array}{ll}\text { EGD } & \text { Esophagogastroduodenoscopy } \\ \text { EoE } & \text { Eosinophilic esophagitis } \\ \text { GERD } & \text { Gastroesophageal reflux disease } \\ \text { PPIs } & \text { Proton-pump inhibitors }\end{array}$




\section{References}

1. Furuta GT, Liacouras CA, Collins MH, Gupta SK, Justinich C, Putnam PE, Bonis P, Hassall E, Straumann A, Rothenberg ME. Eosinophilic esophagitis in children and adults: a systematic review and consensus recommendations for diagnosis and treatment. Gastroenterology. 2007; 133:134263. [PubMed: 17919504]

2. Landres RT, Kuster GG, Strum WB. Eosinophilic esophagitis in a patient with vigorous achalasia. Gastroenterology. 1978; 74:1298-1301. [PubMed: 648822]

3. Attwood SE, Smyrk TC, Demeester TR, Jones JB. Esophageal eosinophilia with dysphagia. A distinct clinicopathologic syndrome. Dig Dis Sci. 1993; 38:109-16. [PubMed: 8420741]

4. Prasad GA, Alexander JA, Schleck CD, Zinsmeister AR, Smyrk TC, Elias RM, Locke GR 3rd, Talley NJ. Epidemiology of eosinophilic esophagitis over three decades in Olmsted County, Minnesota. Clin Gastroenterol Hepatol. 2009; 7:1055-61. [PubMed: 19577011]

5. Straumann A, Simon HU. Eosinophilic esophagitis: escalating epidemiology? J Allergy Clin Immunol. 2005; 115:418-9. [PubMed: 15696105]

6. Ronkainen J, Talley NJ, Aro P, Storskrubb T, Johansson SE, Lind T, Bolling-Sternevald E, Vieth M, Stolte M, Walker MM, Agreus L. Prevalence of oesophageal eosinophils and eosinophilic oesophagitis in adults: The population-based Kalixanda study. Gut. 2007; 56:615-20. [PubMed: 17135307]

7. Dellon ES, Gibbs WB, Fritchie KJ, Rubinas TC, Wilson LA, Woosley JT, Shaheen NJ. Clinical, endoscopic, and histologic findings distinguish eosinophilic esophagitis from gastroesophageal reflux disease. Clin Gastroenterol Hepatol. 2009; 104:2695-2703.

8. Noel RJ, Putnam PE, Rothenberg ME. Eosinophilic esophagitis. N Engl J Med. 2004; 351:940-1. [PubMed: 15329438]

9. Prasad GA, Talley NJ, Romero Y, Arora AS, Kryzer LA, Smyrk TC, Alexander JA. Prevalence and Predictive Factors of Eosinophilic Esophagitis in Patients Presenting With Dysphagia: A Prospective Study. Am J Gastroenterol. 2007; 102:2627-32. [PubMed: 17764492]

10. Mackenzie SH, Go M, Chadwick B, Thomas K, Fang J, Kuwada S, Lamphier S, Hilden K, Peterson K. Clinical trial: eosinophilic esophagitis in patients presenting with dysphagia: a prospective analysis. Aliment Pharmacol Ther. 2008; 28:1140-6. [PubMed: 18624788]

11. Veerappan GR, Perry JL, Duncan TJ, Baker TP, Maydonovitch C, Lake JM, Wong RK, Osgard EM. Prevalence of Eosinophilic Esophagitis in an Adult Population Undergoing Upper Endoscopy: A Prospective Study. Clin Gastroenterol Hepatol. 2009; 7:420-426. [PubMed: 19162236]

12. Desai TK, Stecevic V, Chang CH, Goldstein NS, Badizadegan K, Furuta GT. Association of eosinophilic inflammation with esophageal food impaction in adults. Gastrointest Endosc. 2005; 61:795-801. [PubMed: 15933677]

13. Kerlin P, Jones D, Remedios M, Campbell C. Prevalence of eosinophilic esophagitis in adults with food bolus obstruction of the esophagus. J Clin Gastroenterol. 2007; 41:356-61. [PubMed: 17413601]

14. Rothenberg ME. Biology and treatment of eosinophilic esophagitis. Gastroenterology. 2009; 137:1238-49. [PubMed: 19596009]

15. Okada H, Kuhn C, Feillet H, Bach JF. The 'hygiene hypothesis' for autoimmune and allergic diseases: an update. Clin Exp Immunol. 2010; 160:1-9. [PubMed: 20415844]

16. Chen Y, Blaser MJ. Inverse associations of Helicobacter pylori with asthma and allergy. Arch Intern Med. 2007; 167:821-7. [PubMed: 17452546]

17. Chen Y, Blaser MJ. Helicobacter pylori colonization is inversely associated with childhood asthma. J Infect Dis. 2008; 198:553-60. [PubMed: 18598192]

18. Reibman J, Marmor M, Filner J, Fernandez-Beros ME, Rogers L, Perez-Perez GI, Blaser MJ. Asthma is inversely associated with Helicobacter pylori status in an urban population. PLoS One. 2008; 3:e4060. [PubMed: 19112508]

19. D'Elios MM, Codolo G, Amedei A, Mazzi P, Berton G, Zanotti G, Del Prete G, de Bernard M. Helicobacter pylori, asthma and allergy. FEMS Immunol Med Microbiol. 2009; 56:1-8. [PubMed: 19220467] 
20. Kapel RC, Miller JK, Torres C, Aksoy S, Lash R, Katzka DA. Eosinophilic esophagitis: a prevalent disease in the United States that affects all age groups. Gastroenterology. 2008; 134:1316-21. [PubMed: 18471509]

21. Dixon MF, Genta RM, Yardley JH, Correa P. Classification and grading of gastritis. The updated Sydney System. Am J Surg Pathol. 1996; 20:1161-81. [PubMed: 8827022]

22. Sonnenberg A, Lash RH, Genta RM. A national study of Helicobactor pylori infection in gastric biopsy specimens. Gastroenterology. 2010; 139:1894-1901. e2. quiz e12. [PubMed: 20727889]

23. Collins MH. Histopathologic features of eosinophilic esophagitis. Gastrointest Endosc Clin N Am. 2008; 18:59-71. viii-ix. [PubMed: 18061102]

24. Correa P, Houghton J. Carcinogenesis of Helicobacter pylori. Gastroenterology. 2007; 133:65972. [PubMed: 17681184]

25. Correa P, Piazuelo MB. Natural history of Helicobacter pylori infection. Dig Liver Dis. 2008; 40:490-6. [PubMed: 18396115]

26. Dellon ES, Gibbs WB, Fritchie KJ, Rubinas TC, Wilson LA, Woosley JT, Shaheen NJ. Clinical, endoscopic, and histologic findings distinguish eosinophilic esophagitis from gastroesophageal reflux disease. Clin Gastroenterol Hepatol. 2009; 7:1305-13. quiz 1261. [PubMed: 19733260]

27. Katzka DA. Eosinophilic Esophagitis: From Rookie of the Year to Household Name. Clin Gastroenterol Hepatol. 2008

28. Peery AF, Shaheen NJ, Dellon ES. Practice patterns for the evaluation and treatment of eosinophilic esophagitis. Aliment Pharmacol Ther. 2010; 32:1373-82. [PubMed: 21050240]

29. Markowitz JE, Spergel JM, Ruchelli E, Liacouras CA. Elemental diet is an effective treatment for eosinophilic esophagitis in children and adolescents. Am J Gastroenterol. 2003; 98:777-82. [PubMed: 12738455]

30. Kagalwalla AF, Sentongo TA, Ritz S, Hess T, Nelson SP, Emerick KM, Melin-Aldana H, Li BU. Effect of Six-Food Elimination Diet on Clinical and Histologic Outcomes in Eosinophilic Esophagitis. Clin Gastroenterol Hepatol. 2006; 4:1097-1102. [PubMed: 16860614]

31. Almansa C, Krishna M, Buchner AM, Ghabril MS, Talley N, DeVault KR, Wolfsen H, Raimondo M, Guarderas JC, Achem SR. Seasonal distribution in newly diagnosed cases of eosinophilic esophagitis in adults. Am J Gastroenterol. 2009; 104:828-33. [PubMed: 19240704]

32. Moawad FJ, Veerappan GR, Lake JM, Maydonovitch CL, Haymore BR, Kosisky SE, Wong RK. Correlation between eosinophilic oesophagitis and aeroallergens. Aliment Pharmacol Ther. 2010; 31:509-15. [PubMed: 19925501]

33. Kalach N, Huvenne H, Gosset P, Papadopoulos S, Dehecq E, Decoster A, Creusy C, Dupont C. Eosinophil Counts in Upper Digestive Mucosa of Western European Children: Variations With Age, Organs, Symptoms, Helicobacter pylori Status, and Pathological Findings. J Pediatr Gastroenterol Nutr. 2010

34. Blaser MJ. Helicobacter pylori and esophageal disease: wake-up call? Gastroenterology. 2010; 139:1819-22. [PubMed: 21029801]

35. Straumann A, Bauer M, Fischer B, Blaser K, Simon HU. Idiopathic eosinophilic esophagitis is associated with a $\mathrm{T}(\mathrm{H}) 2$-type allergic inflammatory response. J Allergy Clin Immunol. 2001; 108:954-61. [PubMed: 11742273]

36. Gupta SK, Fitzgerald JF, Kondratyuk T, HogenEsch H. Cytokine expression in normal and inflamed esophageal mucosa: a study into the pathogenesis of allergic eosinophilic esophagitis. J Pediatr Gastroenterol Nutr. 2006; 42:22-6. [PubMed: 16385249]

37. Blanchard C, Wang N, Stringer KF, Mishra A, Fulkerson PC, Abonia JP, Jameson SC, Kirby C, Konikoff MR, Collins MH, Cohen MB, Akers R, Hogan SP, Assa'ad AH, Putnam PE, Aronow BJ, Rothenberg ME. Eotaxin-3 and a uniquely conserved gene-expression profile in eosinophilic esophagitis. J Clin Invest. 2006; 116:536-47. [PubMed: 16453027]

38. Wilson MS, Maizels RM. Regulatory T cells induced by parasites and the modulation of allergic responses. Chem Immunol Allergy. 2006; 90:176-95. [PubMed: 16210910]

39. Kao JY, Zhang M, Miller MJ, Mills JC, Wang B, Liu M, Eaton KA, Zou W, Berndt BE, Cole TS, Takeuchi T, Owyang SY, Luther J. Helicobacter pylori immune escape is mediated by dendritic cell-induced Treg skewing and Th17 suppression in mice. Gastroenterology. 2010; 138:1046-54. [PubMed: 19931266] 
40. Luther J, Owyang SY, Takeuchi T, Cole TS, Zhang M, Liu M, Erb-Downward J, Rubenstein JH, Chen CC, Pierzchala AV, Paul JA, Kao JY. Helicobacter pylori DNA decreases pro-inflammatory cytokine production by dendritic cells and attenuates dextran sodium sulphate-induced colitis. Gut. 2011

41. Genta RM, Lash RH. Helicobacter pylori-negative gastritis: seek, yet ye shall not always find. Am J Surg Pathol. 2010; 34:e25-34. [PubMed: 20631607] 
Table 1

Patient characteristics

\begin{tabular}{|c|c|c|c|}
\hline Clinical Characteristics & Esophageal Biopsies $(n=233,662)$ & $\begin{array}{l}\text { Esophageal and Gastric Biopsies }(n= \\
\qquad 165,017)\end{array}$ & p value $e^{* *}$ \\
\hline Mean age \pm SD & $55.8 \pm 16.2$ & $55.1 \pm 16.5$ & $<0.001$ \\
\hline Children (age < 18) (n, \%) & $3,674(1.6)$ & $3,469(2.1)$ & $<0.001$ \\
\hline Males (n, \%) & $107,759(46.1)$ & $71,488(43.4)$ & $<0.001$ \\
\hline \multicolumn{4}{|l|}{ EGD indication $(\mathrm{n}, \%)^{*}$} \\
\hline Suspected EoE & 26,982 (11.6) & $17,089(10.4)$ & $<0.001$ \\
\hline Dysphagia & $52,787(22.6)$ & $32,055(19.4)$ & $<0.001$ \\
\hline GERD/heartburn & $113,465(48.6)$ & $81,843(49.6)$ & $<0.001$ \\
\hline Barrett's esophagus (screening or follow-up) & $32,257(13.8)$ & $15,816(9.6)$ & $<0.001$ \\
\hline Abdominal pain/dyspepsia & $76,935(32.9)$ & $64,720(39.2)$ & $<0.001$ \\
\hline Chest pain & $9,566(4.1)$ & $6,776(4.1)$ & 0.64 \\
\hline Nausea & $15,218(6.5)$ & $12,426(7.5)$ & $<0.001$ \\
\hline Vomiting & $8,850(3.8)$ & $7,108(4.3)$ & $<0.001$ \\
\hline Weight loss & $6,853(2.9)$ & $5,311(3.2)$ & $<0.001$ \\
\hline Failure-to-thrive & $96(0)$ & $92(0.1)$ & $<0.001$ \\
\hline \multicolumn{4}{|l|}{ Histologic Characteristics (n, \%) } \\
\hline Normal esophageal biopsies & $71,948(30.8)$ & $56,301(34.1)$ & $<0.001$ \\
\hline Any esophageal eosinophilia ${ }^{\dagger}$ & $9,995(4.3)$ & $5,767(3.5)$ & $<0.001$ \\
\hline Histologic eosinophilic esophagitis ${ }^{*}$ & $7,156(3.1)$ & $3,959(2.4)$ & $<0.001$ \\
\hline \multicolumn{4}{|l|}{ Level of esophageal eosinophilia ${ }^{\#}$} \\
\hline$\geq 15 \mathrm{eos} / \mathrm{hpf}$ & $9,981(4.3)$ & $5,791(3.5)$ & $<0.001$ \\
\hline$\geq 45 \mathrm{eos} / \mathrm{hpf}$ & $3,104(1.3)$ & $1,738(1.1)$ & $<0.001$ \\
\hline$\geq 75$ eos/hpf & $1,078(0.5)$ & $607(0.4)$ & $<0.001$ \\
\hline$\geq 90$ eos/hpf & $703(0.3)$ & $388(0.2)$ & $<0.001$ \\
\hline Eosinophilic microabscesses & $2,448(1.0)$ & $1,330(0.8)$ & $<0.001$ \\
\hline Barrett's esophagus on histology & $30,139(12.9)$ & $13,933(8.4)$ & $<0.001$ \\
\hline Reflux esophagitis changes on histology & $79,536(34.0)$ & $55,884(33.9)$ & 0.006 \\
\hline Candidal esophagitis & $4,124(1.8)$ & $2,648(1.6)$ & $<0.001$ \\
\hline CMV esophagitis & $16(0)$ & $9(0)$ & 0.21 \\
\hline HSV esophagitis & $52(0)$ & $29(0)$ & 0.02 \\
\hline Helicobacter pylori on gastric biopsy & $11,170(4.8)$ & $11,170(6.8)$ & $<0.001$ \\
\hline \multicolumn{4}{|c|}{ * Patients could have more than one indication for EGD } \\
\hline \multicolumn{4}{|c|}{$\begin{array}{l}\text { Any esophageal eosinophilia indicates that the examining pathologist noted prominent esophageal eosinophilia, but does not require that the } \\
\text { findings were histologically consistent with EoE in the correct clinical context. This is the main case definition for this study. }\end{array}$} \\
\hline \multicolumn{4}{|c|}{$\begin{array}{l}\text { Histologic eosinophilic esophagitis indicates that the examining pathologist thought that the finding were histologically consistent with EoE in the } \\
\text { correct clinical context. }\end{array}$} \\
\hline
\end{tabular}


**

p values are for the comparison between patients with both esophageal and gastric biopsies $(\mathrm{n}=165,017)$ and those with esophageal biopsies without gastric biopsies ( $\mathrm{n}=68,645)$, and are based on t-test for continuous variables and Pearson's chi-square for categorical variables. 
Table 2

Comparison of patients with esophageal eosinophilia and normal esophageal biopsies

\begin{tabular}{|c|c|c|c|}
\hline & $\begin{array}{l}\text { Any Esophageal Eosinophilia }(n= \\
\qquad, 767)\end{array}$ & $\begin{array}{l}\text { Normal Esophageal Biopsies }(\mathbf{n}= \\
\mathbf{5 6 , 3 0 1})\end{array}$ & p-value \\
\hline Mean age $( \pm \mathrm{SD})$ & $43.9 \pm 16.9$ & $53.2 \pm 17.4$ & $<0.001$ \\
\hline Children age $<18(\mathrm{n}, \%)$ & $345(6.0)$ & $2,165(3.9)$ & $<0.001$ \\
\hline Male (n, \%) & $3,592(62.3)$ & $19,744(35.1)$ & $<0.001$ \\
\hline \multicolumn{4}{|l|}{ EGD indication $(\mathrm{n}, \%)^{\dagger}$} \\
\hline Suspected EoE & $2,110(36.6)$ & $8,640(15.4)$ & $<0.001$ \\
\hline Dysphagia & $2,608(45.2)$ & $11,525(20.5)$ & $<0.001$ \\
\hline GERD/heartburn & $2,535(44.0)$ & $28,100(49.9)$ & $<0.001$ \\
\hline Barrett's esophagus (screening or follow-up) & $252(4.4)$ & $3,372(6.0)$ & $<0.001$ \\
\hline Abdominal pain/dyspepsia & $1,788(31.0)$ & $24,014(42.7)$ & $<0.001$ \\
\hline Chest pain & $191(3.3)$ & $3,183(5.7)$ & $<0.001$ \\
\hline Nausea & $355(6.2)$ & $4,578(8.1)$ & $<0.001$ \\
\hline Vomiting & $266(4.6)$ & $2,519(4.5)$ & 0.629 \\
\hline Weight loss & $99(1.7)$ & $1,716(3.1)$ & $<0.001$ \\
\hline Failure-to-thrive & $8(0.1)$ & $55(0.1)$ & 0.351 \\
\hline
\end{tabular}

* Based on t-test for continuous variables and Pearson's chi-square for categorical variables for the group of patients with both esophageal and gastric biopsies

${ }^{\dagger}$ Patients could have more than one indication for EGD 
Table 3

Comparison of $H$. pylori positive and negative patients

\begin{tabular}{lccc}
\hline & HP positive $(\mathbf{n}=\mathbf{1 1 , 1 7 0})$ & HP negative $(\mathbf{n}=\mathbf{1 5 3 , 8 4 7})$ & p-value* $^{*}$ \\
\hline Mean age $( \pm \mathrm{SD})$ & $56.0 \pm 15.4$ & $55.0 \pm 16.6$ & $<0.001$ \\
Children age $<18(\mathrm{n}, \%)$ & $82(0.73)$ & $3,387(2.2)$ & $<0.001$ \\
Male $(\mathrm{n}, \%)$ & $5,105(45.7)$ & $66,383(43.2)$ & $<0.001$ \\
EGD indication $(\mathrm{n}, \%)^{\dagger}$ & & \\
Suspected EoE & $1,070(9.6)$ & $16,019(10.4)$ & 0.005 \\
Dysphagia & $1,988(17.8)$ & $30,067(19.5)$ & $<0.001$ \\
GERD/heartburn & $5,347(47.9)$ & $76,496(49.7)$ & $<0.001$ \\
Barrett's esophagus (screening or follow-up) & $409(3.7)$ & $15,407(10.0)$ & $<0.001$ \\
Abdominal pain/dyspepsia & $5,017(44.9)$ & $59,703(38.8)$ & $<0.001$ \\
Chest pain & $347(3.1)$ & $6,429(4.2)$ & $<0.001$ \\
Nausea & $786(7.0)$ & $11,640(7.6)$ & 0.041 \\
Vomiting & $455(4.1)$ & $6,653(4.3)$ & 0.207 \\
$\quad$ Weight loss & $531(4.8)$ & $4,780(3.1)$ & $<0.001$ \\
Failure-to-thrive & $4(0)$ & $88(0.1)$ & 0.355 \\
\hline$*$ \\
Based on t-test for continuous variables and Pearson's chi-square for categorical variables \\
${ }^{\dagger}$ Patients could have more than one indication for EGD & &
\end{tabular}


Table 4

Unadjusted and adjusted odds ratios for the association between $H$. pylori and histologic esophageal disease

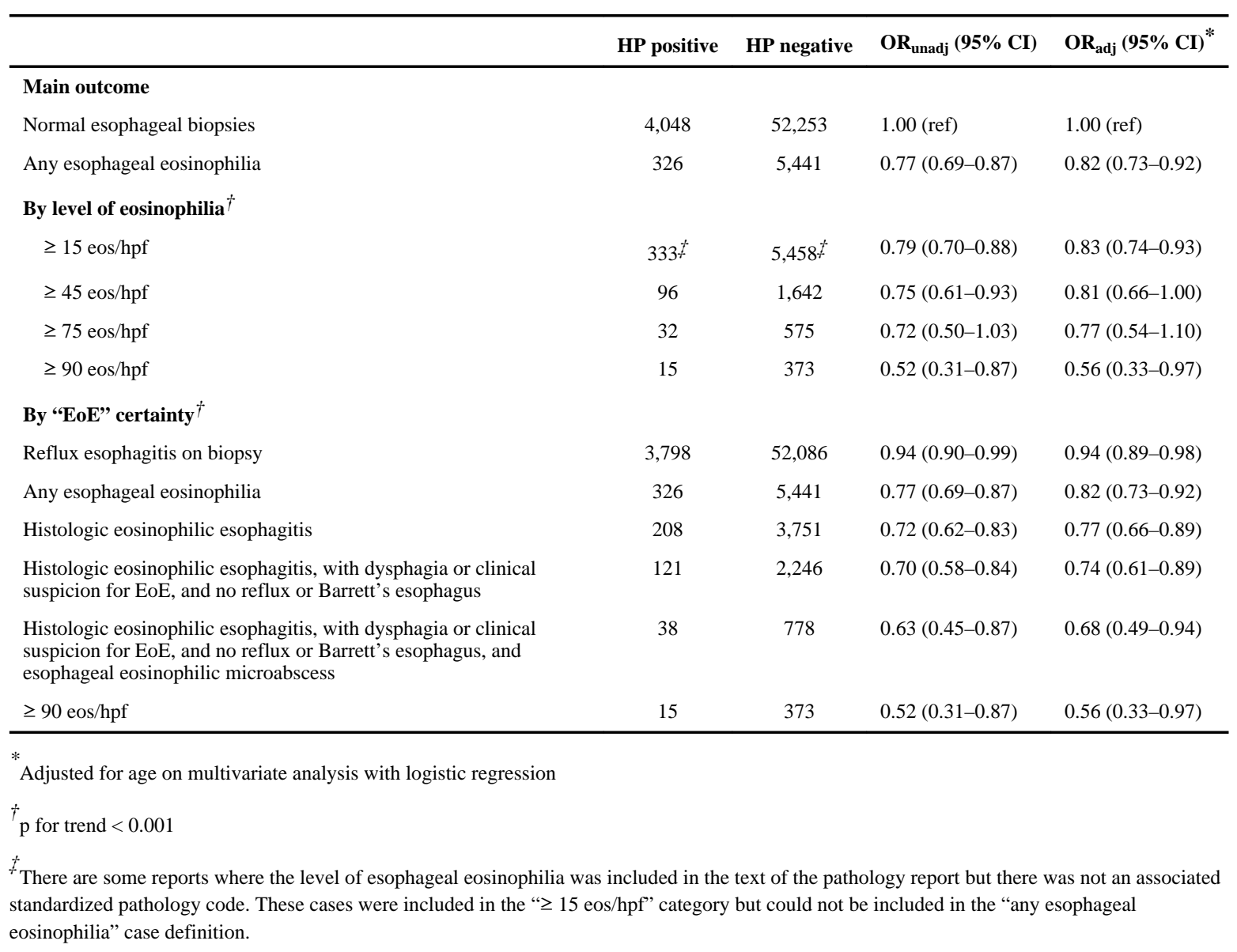


Table 5

Unadjusted and adjusted odds ratios for the association between esophageal eosinophilia and $H$. pylori gastritis

\begin{tabular}{|c|c|c|c|c|}
\hline & $\begin{array}{l}\text { Esophageal eosinophilia } \\
\text { histologically consistent } \\
\text { with EoE }\end{array}$ & No esophageal eosinophilia & $\mathrm{OR}_{\text {unadj }}(95 \% \mathrm{CI})$ & $\mathrm{OR}_{\mathrm{adj}}(95 \% \mathrm{CI})^{*}$ \\
\hline Normal gastric biopsies & 841 & 30,481 & 1.00 (ref) & 1.00 (ref) \\
\hline Chronic active gastritis without HP & 44 & 1,851 & $0.86(0.64-1.17)$ & $1.01(0.74-1.38)$ \\
\hline Chronic active gastritis with HP & 193 & 10,131 & $0.69(0.59-0.81)$ & $0.79(0.68-0.93)$ \\
\hline Intestinal metaplasia ${ }^{\dagger}$ & 25 & 2,641 & $0.34(0.23-0.51)^{*}$ & $0.59(0.40-0.89)^{\dagger}$ \\
\hline
\end{tabular}

* Adjusted for age on multivariate analysis with logistic regression

${ }^{\dagger}$ Includes patients with HP $(\mathrm{n}=7)$ and without HP $(\mathrm{n}=18)$; there was no difference in the OR in these two subgroups.

${ }^{*}$ p for trend $<0.001$ for both the unadjusted and adjusted ORs 